\title{
Adaptação de um curso de alemão em contexto acadêmico para o ensino remoto emergencial através de metodologias ativas
}

\author{
Adaptation of a German course in an academic context for remote emergency teaching through active \\ methodologies
}

Raquel Garcia D’Avilla Menezes

Universidade Estadual do Centro-Oeste - UNICENTRO - Paraná - Brasil

\begin{abstract}
Resumo: Com a suspensão das atividades educacionais em escolas e universidades decorrente da pandemia do COVID-19 e do consequente isolamento social em 2020, muitos professores e aprendizes foram confrontados pela primeira vez com a modalidade de ensino e aprendizagem online. O presente artigo objetiva trazer uma reflexão sobre a adaptação do curso presencial de idiomas da Universidade Estadual do Centro-Oeste (UNICENTRO), mais especificamente do curso de alemão, para a modalidade à distância. Para tanto, é necessário conceituar o ensino remoto e as diferenças metodológicas entre essa modalidade e a educação à distância em contexto brasileiro. À luz do conceito de metodologias ativas de Moran (2015), será apresentado o contexto em que se deu a adaptação do curso presencial de alemão na UNICENTRO para a modalidade online, além das ferramentas e plataformas utilizadas ao longo do semestre letivo. As opiniões dos aprendizes matriculados nesse curso foram coletadas através de um questionário com perguntas fechadas e abertas e geraram os dados ora apresentados, nos quais percebe-se uma adaptação majoritariamente positiva ao formato adotado para as aulas remotas.
\end{abstract}

Palavras-chave: Língua alemã. Ensino de língua estrangeira. Ensino remoto emergencial. Metodologias ativas.

\begin{abstract}
With the suspension of educational activities in schools and universities due to the COVID-19 pandemic and the consequent social isolation in 2020, many teachers and learners were confronted for the first time with the online teaching and learning modality. This article aims to reflect on the adaptation of the face-to-face language course at the State University of the Midwest (UNICENTRO), more specifically the German course, to the distance learning modality. To do so, it is necessary to conceptualize remote teaching and the methodological differences between this modality and distance education in the Brazilian context. In light of Moran's concept of active methodologies (2015), the context in which the face-to-face German course at UNICENTRO was adapted to the online modality will be presented, in addition to the tools and platforms used during the school semester. The opinions of the students enrolled in this course were collected through a questionnaire with closed and open questions and generated the data presented here, in which a mostly positive adaptation to the format adopted for classes in the online mode can be observed.
\end{abstract}

Keywords: German language. Foreign language teaching. Emergency remote teaching. Active methodologies 


\section{Introdução}

No final de 2019 noticiava-se pela primeira vez o surgimento de um novo vírus na cidade chinesa de Wuhan. Em poucos meses, a propagação do coronavírus, que causaria a doença posteriormente nomeada de COVID-19, atingiria diferentes países da Ásia e, mais tarde, todos os outros países do mundo. No Brasil, as primeiras suspeitas de que o vírus teria chegado ao país datam de meados de fevereiro; no começo de março inúmeras instituições de ensino, tanto públicas quanto particulares, suspenderam suas aulas presenciais por tempo indeterminado. Em abril, a paralisação emergencial já afetava 1,6 bilhão de crianças e jovens de 191 países em razão do fechamento de escolas e universidades, o que equivale a $90,2 \%$ de toda a população estudantil mundial (UNESCO, 2020 apud VIERA; RICCI, 2020).

Em um primeiro momento, a maior parte das instituições de ensino demonstraram não possuir preparo para o ensino não presencial, visto que a modalidade à distância exige tempo de organização e professores qualificados para lidarem com tecnologias digitais de informação e comunicação (TDICs). Não só as desigualdades de acesso às TDICs por grande parte da população brasileira e mundial foram escancaradas, como também a necessidade de promover uma aprendizagem que utilize as tecnologias de maneira ativa foram evidenciadas pelo contexto de isolamento social decorrente da pandemia do novo coronavírus (VIERA; RICCI, 2020). isolamento social emergencial levantou inúmeros questionamentos para a área da educação, no que tange a utilização das TDICs. Nas palavras das autoras, o ensino não presencial

Trouxe à tona, também, de forma bastante escancarada, a necessidade de formação docente para este "reinventar da escola", uma vez posta, de forma que nos parece incontornável, a necessidade de finalmente invertermos a chave das práticas pedagógicas, promovendo um ensino ativo - cuja expressão, apesar de repisada, não encontra aplicabilidade efetiva na maior parte dos sistemas educativos - e tornando, a pedagogia, usuária ativa e indutora das tecnologias (VIEIRA; RICCI, 2020, p. 4).
Com a insegurança de retornar às aulas presenciais devido às determinações sanitárias recomendadas pela Organização Mundial da Saúde (OMS), escolas e instituições de ensino superior optaram pela adoção da modalidade online. Com propostas difusas decorrentes, em grande parte, da falta de liderança no Ministério da Educação (MEC), a tomada de decisões ficou a cargo dos estados e municípios brasileiros. Com a publicação em 17 de março da portaria número 343, que ampliava a modalidade à distância emergencial para o ensino superior, as aulas remotas foram e estão sendo ainda implementadas em diferentes universidades públicas e particulares de todo o território brasileiro.

O presente artigo almeja trazer uma reflexão sobre a adaptação do curso presencial de idiomas da Universidade Estadual do Centro-Oeste (UNICENTRO) para a modalidade à distância. A metodologia de pesquisa para a formulação do questionário que gerou os dados aqui apresentados segue a abordagem mista (BORTONIRICARDO, 2008), conjugando, portanto, dados quantitativos e qualitativos. O questionário, cujo tema central é o mapeamento das opiniões dos aprendizes do curso de alemão acerca do ensino remoto emergencial, contém em sua maioria perguntas de múltipla escolha e duas questões abertas.

Após a tabulação dos dados e análise das respostas do questionário, serão apresentados os gráficos que apresentam dados considerados relevantes para o recorte almejado pelo presente trabalho, isto é, que abordam diretamente a opinião dos aprendizes quanto ao formato do curso. Para discutirmos as respostas dos aprendizes participantes do questionário e as ações pedagógicas implementadas no curso, faz-se necessário entender em que contexto se deu a implementação do ensino remoto emergencial e que diferenças há entre essa modalidade online e a educação à distância (EaD).

Sendo assim, o presente trabalho relata os avanços da modalidade EaD no Brasil antes do contexto de isolamento social e as diferenças desse modelo para o ensino remoto emergencial (ERE). Posteriormente será apresentado o contexto em que se deu a adaptação do curso presencial de alemão na UNICENTRO para a modalidade online $\mathrm{e}$ as opiniões dos aprendizes matriculados nesse curso, coletadas através de um 
questionário, sobre o formato de adaptação para o online e quanto as suas experiências individuais frente ao ERE.

\section{Panorama da EaD no Brasil pré-pandemia}

A EaD no Brasil tem seu início no século XIX, quando ainda era chamada de teleducação. No entanto, a modalidade à distância só passou a ser regulamentada em 1996 com a publicação da LDB (lei de diretrizes e bases da educação nacional número 9394). Brahim (2012) percebe que as gerações de $\mathrm{EaD}$ indicam mudanças paradigmáticas em razão do avanço das TDICs. Em seu artigo, a autora lista cinco gerações da EaD no país, sendo a primeira através de materiais impressos e enviados pelos Correios, enquanto a quinta já conta com equipamentos sem fio. Brahim salienta, porém, que os avanços de uma geração não anulam os de outra.

O MEC traz a seguinte definição de EaD

Para os fins deste Decreto, caracteriza-
se a Educação a Distância como
modalidade educacional na qual a
mediação didático-pedagógica nos
processos de ensino e aprendizagem
ocorre com a utilização de meios e
tecnologias de informação e
comunicação, com estudantes e
professores desenvolvendo atividades
educativas em lugares ou tempos
diversos (PLANALTO, 2009 apud
BRAHIM, 2012, p. 33)

À época da publicação de um levantamento feito por Santos e Wechsler (2009), a EaD destacava-se na área médica. Embora tal levantamento esteja desatualizado devido a sua data de publicação, é pertinente perceber uma curva ascendente do interesse pelas novas tecnologias em todas as áreas de conhecimento. O interesse crescente pela $\mathrm{EaD}$ tem diferentes motivações; destaca-se aqui, por exemplo, a possibilidade de inclusão de aprendizes moradores de zonas rurais, aprendizes portadores de deficiência físicomotora, aprendizes com acesso limitado ou nulo a meios de transporte, dentre outros. Ou seja, a vontade e a necessidade de ampliar o acesso à educação têm funcionado como incentivo à EaD.

A EaD ocorre, primordialmente, no chamado ambiente virtual de aprendizagem (AVA). É no AVA, portanto, que docentes utilizam tecnologias para 0 desenvolvimento de suas práticas educativas, tais como a administração da participação dos aprendizes e do fluxo de atividades a serem trabalhadas conforme 0 planejamento da instituição onde atuam. Todavia, a prática com o AVA não ocorre sem obstáculos. Silva et al (2017) atestam em um estudo com professores de instituições de ensino superior que a modalidade presencial ainda funciona como guia norteador para as ações docentes online. Os autores relatam que os impeditivos relacionados à $\mathrm{EaD}$ vão além de obstáculos puramente tecnológicos; eles perpassam a formação pedagógica voltada para o uso crítico de TDICs, visto que replicar o modelo presencial na modalidade à distância não é garantia de sucesso das atividades planejadas (ibid., 2017, p. 694).

\section{3 isolamento social e a imposição do ensino remoto emergencial}

Dadas as circunstâncias anteriormente descritas, nas quais o isolamento social fez com que as instituições de ensino suspendessem as aulas presenciais, a solução encontrada para que crianças e jovens não ficassem sem contato com conteúdos educacionais foi a implementação do ensino remoto emergencial. Equivocadamente chamada de EaD pelas grandes mídias, o ensino remoto se difere exatamente por seu caráter transitório. Embora ambas as modalidades ocorram online, a EaD é planejada para ser implementada de maneira remota, podendo ou não contar com aulas presenciais. Já o ensino remoto é definido primordialmente pela adaptação passageira do presencial para o online.

Ensinar remotamente não é sinônimo de ensinar a distância, embora esteja diretamente relacionado ao uso de tecnologia e, nesse caso, digital. $\mathrm{O}$ ensino remoto permite o uso de plataformas já disponíveis e abertas para outros fins, que não sejam estritamente os educacionais, assim como a inserção de ferramentas auxiliares e a introdução de práticas inovadoras (GARCIA et al., 2020, p. 5).

O ensino remoto ocorre, de modo geral, em tempo semelhante à educação presencial, com a transmissão de conteúdo através de videoconferências síncronas que podem vir a ser gravadas e disponibilizadas no formato de videoaulas de maneira assíncrona. Assim sendo, o ensino remoto traz desafios próprios dessa adaptação, tais como a permanência até o final do curso por parte de 
aprendizes que não se propuseram a estudar remotamente. Arruda (2020) lista outras particularidades de uma modalidade de caráter emergencial, como por exemplo a manutenção do acesso contínuo aos conteúdos, dificuldade dos docentes de realizar leituras corporais, dificuldade de manter o AVA interativo, dentre outros. Na opinião do autor, existe ainda hoje o estigma de que a modalidade online teria qualidade inferior àquela presencial, interferindo assim negativamente na motivação desses aprendizes e docentes para interagirem através de TDICs.

Além disso, especialistas da área afirmam que o excesso de videoconferências causa exaustão, fenômeno ao qual deu-se o nome de fatiga zoom (zoom fatigue em inglês, referente à plataforma estadunidense para videoconferências). Uma das razões citadas em reportagens sobre o fenômeno de fatiga é o fato de a habilidade em interpretar sugestões não verbais ficaria prejudicada, causando consequente estresse ao corpo. Neste sentido, Arruda (2020) salienta sobre a importância de integrar tecnologias de informação ao currículo da formação de futuros professores. Indo de encontro à integração de tecnologias no ensino remoto emergencial (ERE), o contexto educacional no qual elas foram aplicadas será apresentado a seguir.

\section{0 isolamento social no contexto do Programa} Multicultural de Línguas

\subsection{Matrículas e desistências para a implementação do ERE}

O Programa Multicultural de Línguas (PROMUL) se trata de um programa de extensão alocado no departamento de Letras da UNICENTRO, cujas aulas são ministradas nos dois campi da universidade, situada na cidade de Guarapuava, no Paraná. O objetivo do PROMUL, como consta no site do programa, é "facilitar o acesso de toda a comunidade a novos idiomas". A equipe pedagógica do programa é composta atualmente por sete professores colaboradores e são ofertados cursos de alemão, espanhol, francês e inglês. Embora o programa seja primordialmente voltado para atender à comunidade acadêmica da própria universidade, todos os cursos são abertos à comunidade local e permitem a matrícula de aprendizes a partir dos 14 anos de idade.
Dada a situação de isolamento social decorrente da pandemia do COVID-19, a equipe pedagógica do PROMUL formulou um questionário que tinha como objetivo averiguar o interesse em aderir ao ERE por parte dos aprendizes matriculados nos cursos ofertados no primeiro semestre de 2020. A secretaria do programa encaminhou por e-mail, então, um questionário àqueles matriculados nos cursos. Em março de 2020 havia 307 matrículas, considerando todos os quatro idiomas ofertados pelo programa. Do número total de matrículas, somente 187 questionários retornaram com respostas, tendo sido quatro deles descartados por motivos de duplicidade (aprendizes matriculados em dois idiomas e/ou envio repetido do formulário), totalizando assim 183 respondentes. Dos 183 formulários válidos, 127 demonstravam interesse e consequente aceite do ERE e 56 indicavam seu não aceite.

A média de desistentes por curso se mostrou similar em todos os idiomas; no entanto, as turmas iniciantes contaram com um número considerável de desistências e trancamento de matrícula quando comparadas com as turmas mais avançadas de continuação. A exemplo do curso de língua alemã, houve o total de 57 matrículas, das quais 36 aprendizes responderam ao formulário. Desses 36 respondentes, 18 pessoas optaram por continuar o curso na modalidade online. Em uma das turmas de Alemão I, por exemplo, 5 (de um total de 10) trancaram suas matrículas, enquanto no Alemão III apenas 2 (de um total de 8 ) decidiram não continuar.

Os números de aprendizes matriculados nos três níveis de língua alemã ofertados mudaram ao longo do primeiro semestre, com pessoas que optaram por continuar, mesmo não tendo participado da pesquisa inicial, e pessoas que trancaram suas matrículas após o primeiro mês de aulas. O recorte de análise dos dados em detrimento da língua alemã deu-se pelo fato de esse idioma ter sido implementado por último, ou seja, após os cursos de inglês, espanhol e francês já fazerem parte do PROMUL, mesmo a UNICENTRO estando localizada no município de Guarapuava, onde há a colônia alemã Entre Rios e o colégio alemão Imperatriz. Assim sendo, o curso de alemão se mostra o mais flexível no processo de adaptação à modalidade online por não ter longa tradição no programa. 
4.2. Perfil dos aprendizes do curso de alemão do PROMUL

O projeto pedagógico do PROMUL prevê seis níveis referentes ao curso de língua alemã, no qual o nível Alemão I corresponde ao iniciante A1.1, segundo o Quadro Europeu Comum de Referência para Línguas (QECR). O Alemão VI corresponde, por conseguinte, ao nível intermediário B1.2. No primeiro semestre de 2020 foram ofertados os quatro primeiros níveis, i.e., turmas do Alemão I ao Alemão IV; desses níveis, somente os níveis Alemão I, Alemão II e Alemão III foram confirmados. Para que uma turma seja confirmada, é necessário que haja ao menos cinco aprendizes matriculados naquele nível. $\mathrm{Na}$ modalidade presencial, havia 57 pessoas matriculadas nos três níveis confirmados do curso de língua alemã, como foi mencionado anteriormente. Após a implementação do ERE, as aulas online iniciaram-se no dia 11 de maio de 2020, e o número total de aprendizes nas quatro turmas, sendo duas delas de Alemão I, foi de 39 pessoas.

O questionário formulado por mim, o qual gerou os dados que se seguem, foi respondido por 25 aprendizes, ou seja, por um pouco mais da metade do total de matriculados no ERE. A maior parte dos respondentes no curso de língua alemã do PROMUL se identificam com o gênero masculino e têm entre 18 e 24 anos de idade. 52\% dos respondentes estavam na graduação à época do questionário. Dessas 39 pessoas, 20 cursavam o Alemão I, 13 o Alemão II e 6 cursavam o Alemão III. Embora mais aprendizes cursem o primeiro nível, percebe-se que 0 maior número de respondentes está matriculado no Alemão II, como é possível observar no gráfico 1. Todos os gráficos consideram alemão como substituto para o termo Deutsch no original.

Gráfico 1 - Parcela de aprendizes matriculados no curso de alemão

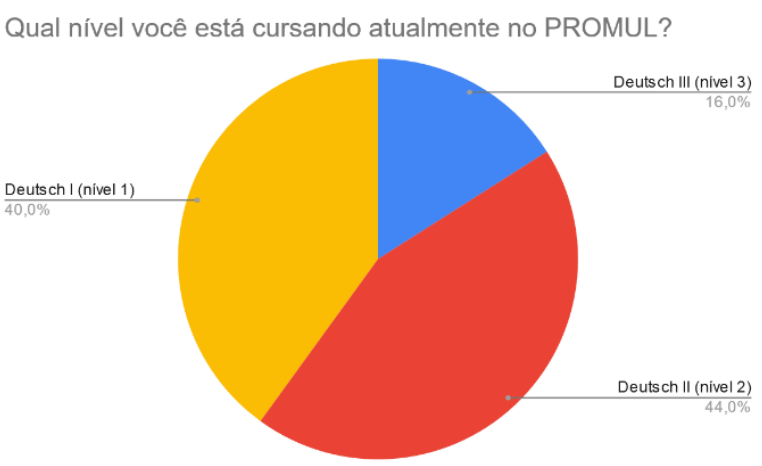

A desistência ao longo dos cursos de alemão não é exclusiva do PROMUL e tem razões intrínsecas ao processo de aprendizagem de um idioma não latino no Brasil. Em razão de o presente artigo não ter como foco quais motivações levam os aprendizes a desistirem do curso, não cabe no escopo do presente trabalho debater as razões para tal. Para saber mais sobre a relação de fatores, tais como motivação e trancamento de matrículas em cursos de alemão, sugiro os trabalhos de Couto (2011) e Rozenfeld (2011).

\subsection{A sala de aula invertida como recurso metodológico no ERE}

Para que ocorra uma mudança profunda dos métodos tradicionais para metodologias ativas, fazem-se necessários alguns ajustes do atual paradigma pedagógico, conforme aponta Moran (2015). A inversão da lógica tradicional, dando lugar à sala de aula invertida, é uma possibilidade que abrange tanto a EaD quanto a modalidade de educação presencial. O professor passa a ser visto não mais como detentor único de conhecimento, mas sim como orientador e tutor. Também os aprendizes assumem controle do próprio processo de aprendizagem e deixam de exercer um papel passivo em sala de aula.

Moran (2015, p. 19) salienta ainda que "nas metodologias ativas de aprendizagem, o aprendizado se dá a partir de problemas e situações reais; os mesmos que os alunos vivenciarão depois na vida profissional, de forma antecipada, durante o curso". Ainda segundo o autor, a melhor maneira de envolver os aprendizes na metodologia da sala de aula invertida é "negociando com eles as melhores formas de realizar o projeto, valorizando cada etapa e principalmente a apresentação e a publicação em um lugar virtual visível do ambiente virtual para além do grupo e da classe" (ibid., 2015, p. 19).

Em outras palavras, as metodologias ativas são aquelas que invertem a lógica tradicional de ensino e aprendizagem. No AVA ficam concentradas informações consideradas básicas, enquanto na sala de aula - virtual ou presencial - essas informações e conhecimentos preliminares são postos em prática de maneira criativa e supervisionada pelo professor-tutor. Esse modelo pressupõe, no entanto, que professores e aprendizes tenham acesso à banda larga de internet e algum domínio das TDICs. Embora de extrema relevância para o debate do sucesso da implementação da EaD e do ensino remoto 
no Brasil, esses fatores parecem não configurar uma problemática para os aprendizes do PROMUL matriculados no curso de alemão.

Gráfico 2 - Acesso às TDICs por parte dos aprendizes de alemão

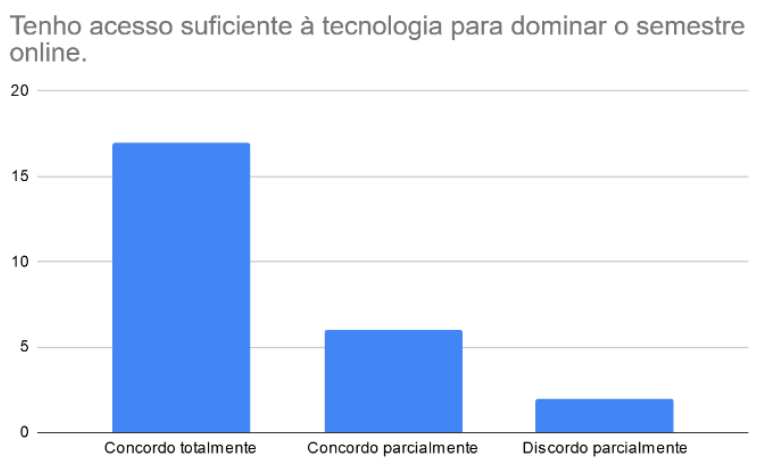

Como é possível notar no gráfico 2, a maior parte dos aprendizes respondentes afirmam ter acesso suficiente à tecnologia, concordando totalmente ou parcialmente. Não houve sequer uma resposta completamente negativa, tendo sido a opção "discordo parcialmente" assinalada por duas pessoas. A mesma tendência se repetiu com as afirmações "tenho uma conexão de internet adequada" e "tenho um espaço de trabalho disponível para cumprir plenamente minhas tarefas de estudo".

\subsection{Visão geral dos recursos utilizados no curso de alemão durante o ERE}

Ficou a critério de cada professor qual plataforma e qual livro didático adotar para ministrar as aulas dos cursos no âmbito do PROMUL. Neste sentido, o livro didático adotado para o curso de alemão foi a série Menschen da editora Hueber e os encontros remotos ocorreram através da plataforma de videoconferência Zoom. A escolha por esta plataforma deu-se pela possibilidade de organizar salas virtuais individuais, recurso não disponível em outras plataformas gratuitas. Para que os materiais básicos pudessem ser disponibilizados da maneira mais acessível e prática possível, foram criados tanto grupos de Whatsapp, quanto turmas no ambiente virtual do Google Classroom. Enquanto os grupos de Whatsapp tinham a função de transmitir recados rápidos e fomentar a interação entre os aprendizes, as turmas do Google Classroom serviram como uma espécie de portfólio do conteúdo aprendido ao longo do semestre, através da disponibilização de exercícios e materiais complementares para os encontros síncronos.

Os encontros síncronos tiveram duração de três horas-aula semanais, ocorrendo sempre no horário estipulado no ato da matrícula. Os encontros foram gravados e disponibilizados posteriormente àqueles que, por qualquer motivo, não puderam comparecer à aula. Durante os encontros, os aprendizes podiam se comunicar oralmente utilizando o microfone ou por escrito pelo bate-papo integrado à plataforma Zoom. Para exercícios escritos e colaborativos, utilizou-se majoritariamente 0 site edupad.ch, que permite que todos possam digitar concomitantemente e ter seus textos reconhecidos pelo uso de uma cor predominante, como é possível observar na figura 1.

Figura 1- Exemplo de textos no Edupad

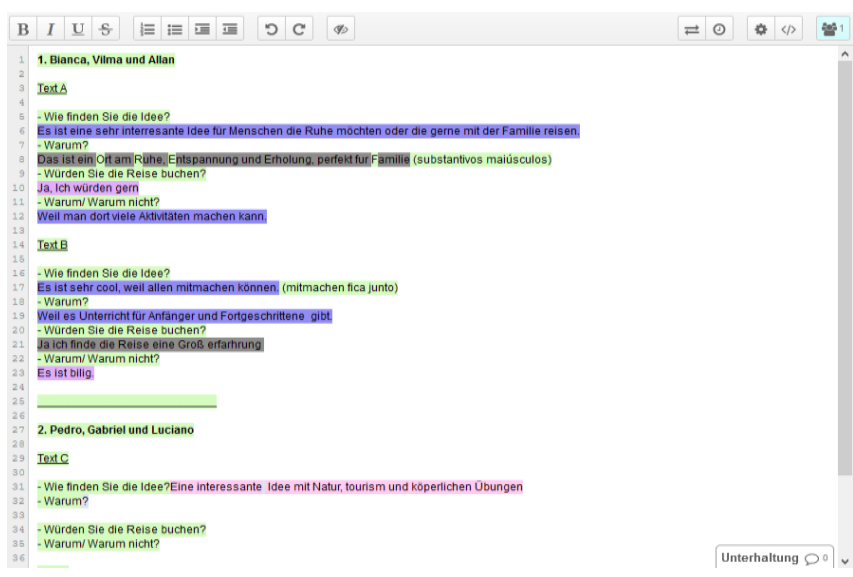

Outras ferramentas utilizadas foram os sites (1) IdeaBoardz, que simula a criação de post-its, (2) MindMeister, que permite a elaboração de mapas mentais, (3) KudoBox, que possibilita redigir um cartão postal e enviá-lo por e-mail ao destinatário da mensagem, (4) Padlet, para a criação de murais interativos e que permite a anexação de vídeos e fotos, (5) ComixMaker, que traz personagens pré-definidos para criação de uma história em quadrinhos, a exemplo da figura 3, e (6) Kahoot.it, que possibilita a elaboração de jogos interativos. Essas e outras ferramentas foram utilizadas mais de uma vez em diferentes atividades ao longo do semestre, tais como, 
por exemplo, revisão de vocabulário e criação de diálogos. É importante salientar que todas as ferramentas utilizadas ao longo do semestre são gratuitas ou disponibilizam uma versão básica sem custos.

Figura 2 - Mapa mental criado no Mindmeister

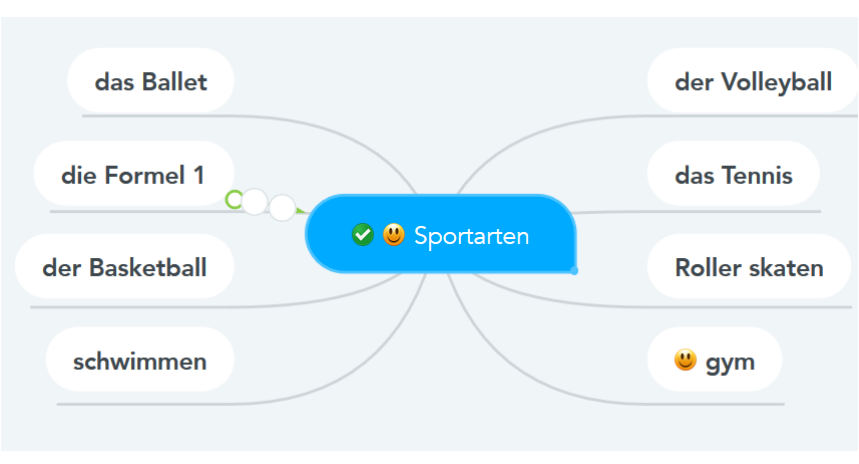

Como já mencionado, a plataforma Zoom destaca-se das demais pela integração de recursos pedagógicos, como por exemplo o compartilhamento de tela com um quadro branco e a separação de participantes em salas individuais ou em grupos. A exemplo da figura 2, a maioria das atividades de revisão de vocabulário e estruturas vistos em encontros anteriores ocorria majoritariamente através de ferramentas de brainstorming, nas quais cada aprendiz pode contribuir com palavras, frases, estruturas e afins. Pelas contribuições nestas ferramentas serem anônimas, não foi possível perceber se os aprendizes sentiram receio ou "medo" em errar, como pode acontecer na aula presencial.

Já a oralidade foi fomentada, não só na sala principal, através da leitura em voz alta de pequenos trechos de exercícios presentes no livro didático, como - e principalmente - em trabalhos em grupo nas salas individuais. A depender do tema e da atividade proposta, foram utilizadas aqui ferramentas de criação de histórias e cartazes, anexados no mural da turma no Google Classroom (vide como exemplo a figura 3). Veremos na seção a seguir que nem todos os aprendizes se sentiram confortáveis em interagir com os colegas de turmas, principalmente se considerarmos que nas duas turmas de Alemão I as pessoas não se conheceram presencialmente como nas turmas de continuação de Alemão II e de Alemão III.

Figura 3 - História em quadrinhos elaborada no ComixMaker

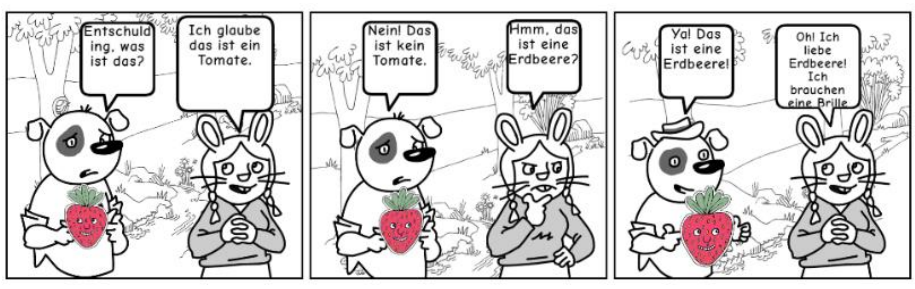

5 Opinião dos aprendizes sobre o processo de aprendizagem no ensino remoto emergencial

Conceituar "opinião" em contexto educacional é relativamente complexo, dado que na literatura existem conceitos sinônimos como por exemplo "representações dos aprendizes" (HOLEC, 1987) e "cultura de aprender línguas" (ALMEIDA FILHO, 1993), que, no entanto, conceituam o mesmo fenômeno. Em termos gerais, entende-se por opinião o conjunto de expectativas e suposições individuais. Embora não exista uma definição única para as impressões que aprendizes têm dos processos de ensino e aprendizagem, parte-se, no presente artigo, da definição de Barcelos (2004).

Conhecimento intuitivo implícito ou explícito dos aprendizes. Esse conhecimento é compatível com sua idade e nível socioeconômico, é baseado na sua experiência educacional anterior, leituras prévias e contatos com pessoas influentes. (BARCELOS, 2004, p. 131)

Nos gráficos resultantes das perguntas quantitativas é possível perceber alguma divergência entre necessidades individuais e interesses pessoais. Em uma análise mais geral, poucos foram os respondentes que realmente demonstraram enfrentar algum tipo de dificuldade em relação à adaptação do curso ao modelo de ERE. Como é possível observar no gráfico 3, a maior quantidade de respondentes assinalou não concordar nem discordar da afirmação sobre o ensino remoto permitir uma melhor adaptação à rotina de estudos.

\section{Gráfico 3 - Sobre a rotina de estudos online}


O semestre online me permite adaptar melhor meu aprendizado diário à minha rotina.

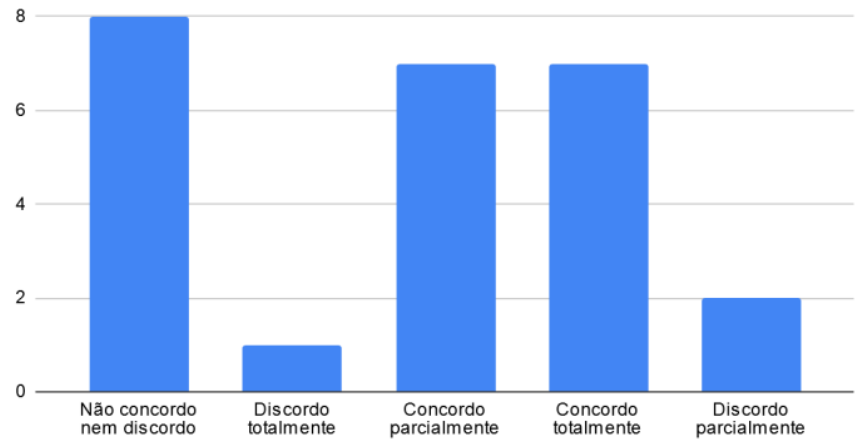

Considerando "A" para denominar a palavra "aprendiz", foram selecionadas as respostas mais completas, nas quais era possível apreender a relação causa e consequência; as respostas descartadas estavam incompletas e não permitiam, assim, um entendimento aprofundado. A primeira pergunta aberta do questionário se referiu a uma possível vontade e/ou necessidade de trancar a matrícula: "Quando foi divulgado que o semestre ocorreria excepcionalmente online, você logo escolheu continuar ou considerou trancar sua matrícula? Por quê?". Erros de grafia e pontuação não foram corrigidos por serem considerados de pouca importância para o propósito da presente pesquisa.

A3: Escolhi fazer pois como as aulas da minha universidade foram suspensas eu poderia me dedicar ao alemão nesse período e como não tive experiencia com o EAD resolvi dar uma chance.

A5: Escolhi continuar por mesmo online já me traria conhecimento, e eu quero aprender.

A13: Considerei trancar, pois não tenho facilidade em aprendizado à distância.

A15: Escolhi continuar. Pois prefiro aprender online do que ficar sem aula.

A25: Considerei trancar, por causa da pandemia e a alteração nos meus horários

A segunda pergunta aberta tematizou as ferramentas utilizadas e citadas na seção anterior, à luz da metodologia da sala de aula invertida: "Qual(is) atividade(s) e/ou dinâmica(s) já utilizadas te agradaram mais e quais menos? Por quê?". Aqui podemos perceber a dificuldade em adaptar a metodologia ativa a todos os interesses individuais, mesmo que a maioria das respostas tenha cunho positivo, como é perceptível nos trechos que se seguem. Talvez a maior divergência de opiniões se deu no que tange aos trabalhos em grupos nas salas individuais, corroborado pelos dados do gráfico 4 .

A3: O uso dos sites como edupad, o site de jogos, e todos os sites que a professora usa me agradam bastante e fazem com que eu fixe melhor 0 conteúdo. As revisõezinhas no começo de cada aula também são de grande valia. O que menos me agrada é minha conexão com a internet mesmo.

A7: Os que nós separamos em pequenos grupos e fizemos uma atividade, pois sinto que tenho maior liberdade para falar.

A13: As atividades em sites personalizados achei um diferencial, mas separar pra fazer atividades online em dupla não deram muito certo.

A15: Gostei bastante das atividades com interação, como escrever em post it e revisar pronúncia, ou então em salas individuais em duplas. Não gosto muito quando são lançadas perguntas e todo mundo deve responder um de cada vez, acho que enrola a aula e temos pouco proveito.

A17: As salas de vídeo "separadas" são ótimas, muito mais fácil de trabalhar em grupos menores.

A25: Gosto da conversação com os outros alunos, mas a distância e pela falta de nos conhecermos atrapalha um pouco.

Trabalhos em grupo me parecem um obstáculo intransponível no momento.

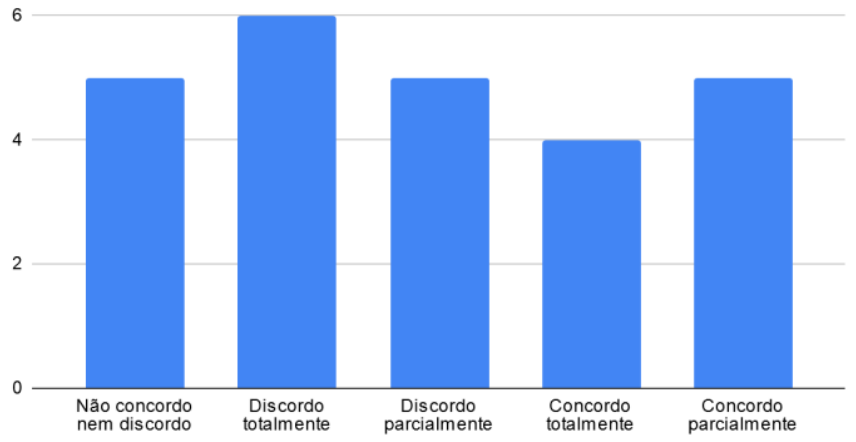

Ao final do questionário, foi disponibilizada uma caixa de respostas para contribuições e comentários gerais, com a seguinte pergunta: "Você tem algum comentário ou observação? A sua opinião é importante para mim". A maioria dos respondentes deixou a caixa em branco, visto que ela não estava marcada como obrigatória. Entretanto, gostaria de destacar algumas contribuições de aprendizes que, mesmo afirmando não terem percebido um rendimento individual igual aquele usual na modalidade de aulas presenciais, sugerem que a modalidade EaD seja adotada pelo PROMUL em um cenário pós-pandemia.

A4: Acredito que o metodo $\mathrm{EaD}$ é valido sim para estudos, venho aprendendo muito, mas digo que, em sala de aula presencial sempre sera mais eficaz. 
Mas nao descartem remover o EaD apos essa pandemia.

A9: Sugiro a possibilidade de termos mais atividades escritas como tarefa de casa. Por exemplo, pequenos textos sobre um assunto que já vimos. Eu pessoalmente gosto muito de escrever. No mais, tenho gostado muito das aulas, são bem dinâmicas com as atividades variadas que estamos tendo. Eu achei que seria cansativo o curso por ser online, mas não está sendo. $E$ imagino que deva estar sendo muito desafiador construir aulas alternativas, então quero parabenizar a professora pelo esforço e dedicação em preparar atividades criativas pra gente. Está sendo ótimo! Ps. os jogos de memória são ótimos! ich liebe!

A10: Prefiro continuar com as aulas por videoconferência à presencial. Fico com receio de comparecer à Faculdade, principalmente em horário noturno por causa de segurança, assaltos, a praça e as ruas no entorno da faculdade são muito escuras. Fico com medo de ser assaltada nas redondezas da Unicentro enquanto estiver estacionando ou saindo das aulas.

A15: Estou muito satisfeita com a dedicação da professora em dar a melhor aula possível dentro das limitações atuais.

A22: A aula online não substitui a aula presencial, a transmissão de conteúdo fica comprometida e o rendimento na aprendizagem cai significativamente. Apesar de não ter conhecimento prévio, no nível I eu consegui acompanhar e aprender bem. Ja no módulo II eu não estou conseguindo aprender. Tô com muita dificuldade.

Também no gráfico 5 vemos que não há unanimidade sobre a possível adoção de TDICs na modalidade presencial em um cenário pós-pandemia.

Embora as respostas "concordo parcialmente" e "concordo totalmente" tenham sido assinaladas pela maioria dos respondentes, os números daqueles que discordaram, parcialmente ou totalmente, são igualmente altos. Seria possível presumir que por "métodos digitais", os respondentes que discordaram entendam a $\mathrm{EaD}$ e não necessariamente as ferramentas propriamente ditas, visto a distorção desse conceito nas grandes mídias, como já mencionado.

Gráfico 5 - Sobre a adoção de TDICs na modalidade presencial

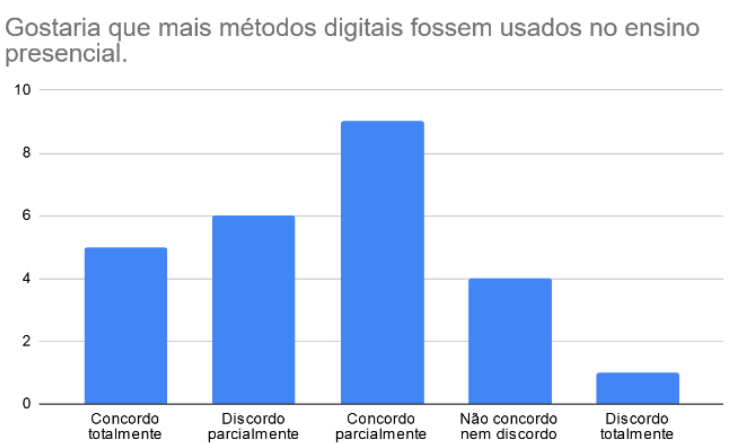

\section{Conclusão e perspectivas da EaD pós- pandemia}

Diferente dos dados trazidos por Vieira e Ricci (2020, p. 4) e Arruda (2020, p. 259), que revelam uma enorme defasagem entre o crescente interesse pela EaD e o limitado acesso às TDICs e à banda larga de internet, os aprendizes matriculados nos cursos de alemão do PROMUL não enfrentaram grandes dificuldades em acompanhar as aulas durante o ERE. Mesmo assim, foi perceptível que nem todos se sentiram confortáveis na modalidade online e algumas pessoas chegaram a relatar durante os encontros que não conseguiram participar por motivos técnicos (queda de energia, computador quebrado, etc). É possível perceber os enfrentamentos por parte de professores e aprendizes no ERE, durante a situação de pandemia do COVID-19, deverá servir de legado para repensar o currículo de escolas e universidades pós-pandemia.

Minha hipótese é a de que, no
paradigma educacional pós Covid-19, a
divisão entre educação a distância e
educação presencial perderá o
significado e que o novo "normal" será a
educação mediada por recursos
educacionais digitais (MARTINS, 2020,
p. 245).

Ainda na opinião de Martins (2020, p. 254), a $\mathrm{EaD}$ na pós-pandemia deverá focar sobretudo nas condições de trabalho docente e no desenvolvimento de práticas pedagógicas centradas no aprendiz. Saliento, neste sentido, que a falta de familiaridade com as TDICs em contextos de aprendizagem ao longo da educação básica é percebida também em contexto acadêmico, como uma espécie de herança pouco frutífera. O aprendiz muitas vezes não exerce a autonomia no próprio processo de aprendizagem porque simplesmente não aprendeu a exercitá-la durante as aulas tradicionais, majoritariamente voltadas para o professor.

Ao sugerir a metodologia da sala de aula invertida, Moran (2015, p. 18) propõe não apenas mudanças metodológicas, mas mudanças profundas no sistema educacional, que redesenhariam o envolvimento dos aprendizes no próprio processo de aprendizagem a partir de projetos e desafios. A 
reelaboração da EaD - e por que não dizer também da educação presencial - pressupõe a criação de desafios, cujo ponto de partida e de chegada é a reflexão, perpassada pela utilização de tecnologias adequadas. Antes tida como impossível ou mesmo utópica, a inclusão de TDICs nas escolas e universidades não só se mostra necessária, como também desejada por grande parte dos aprendizes.

\section{REFERÊNCIAS}

ARRUDA, Eucidio. Educação remota emergencial: elementos para políticas públicas na educação brasileira em tempos de Covid-19. EmRede, v. 7, n. 1, p. 257-275, 2020.

BARCELOS, A. Crenças sobre aprendizagem de línguas, linguística aplicada e ensino de línguas. Linguagem e ensino, vol. 7, n. 1, p. 123-156. Minas Gerais, 2004

BORTONI-RICARDO, Stela Maris. O professor pesquisador: introdução à pesquisa qualitativa. Ed. Parábola. São Paulo, 2008.

BRAHIM, Adriana. O processo de tutoria na EaD: uma prática pedagógica articulada à luz da Teoria Histórico-Cultural. Revista Intersaberes, v. 7 n. 13, p. 29-45, 2012.

FERREIRA, Philip. Como será realmente a escola pós-pandemia?. Jornal de Brasília, 19 de maio de 2020. Disponível em $<$ https://jornaldebrasilia.com.br/blogs-ecolunas/educar-acao/como-sera-realmente-a-escolapos-pandemia/>. Acesso em: 13 de ago. 2020.

GARCIA, Tânia et al. Ensino remoto emergencial: proposta de design para organização de aulas. SEDIS, UFRN, 2020.

MARTINS, Ronei. A covid-19 e o fim da educação a distância: um ensaio. EmRede, v. 7, n. 1, p. 242-256, 2020.

MORAN, José Manuel. Mudando a educação com metodologias ativas. Coleção Mídias Contemporâneas. Convergências Midiáticas, Educação e Cidadania: aproximações jovens, v.2, 2015.

SANTOS, Eliana; WECHSLER, Solange. Ensino à distância: uma década das publicações científicas brasileiras. Interamerican Journal of Psychology, v. 43, n. 3, p. 558-565, 2009.

SILVA, Alda et al. Os impedimentos da atividade de trabalho do professor na EAD. Psicol. cienc. prof., Brasília, v. 37, n. 3, p. 683-696, 2017.
VIEIRA, Letícia; RICCI, Maike. A educação em tempos de pandemia: soluções emergenciais pelo mundo. Editorial do Observatório do Ensino Médio em Santa Catarina. Santa Catarina, 2020. Disponível em <https://www.udesc.br/arquivos/udesc/id_cpmenu/743 2/EDITORIAL_DE_ABRIL_Let_cia_Vieira_e_Maike _Ricci_final_15882101662453_7432.pdf>. Acesso em: 20 de ago. 20

GARCIA D'AVILA MENEZES, Raquel. Adaptação de um curso de alemão em contexto acadêmico para o ensino remoto emergencial através de metodologias ativas. Signo, Santa Cruz do Sul, v. 46, n. 85, p. 170-179, jan. 2021. ISSN 1982-2014. Disponível em: $<$ https://online.unisc.br/seer/index.php/signo/article/view/ 15675>. doi:https://doi.org/10.17058/signo.v46i85.15675. 